\title{
GENERIC PATTERNS AND SOCIO-CULTURAL RESOURCES IN ACKNOWLEDGEMENTS ACCOMPANYING ARABIC Ph.D. DISSERTATIONS ${ }^{1}$
}

\author{
Mohammed Nahar Al-Ali
}

\begin{abstract}
Even though the acknowledgement genre is a common practice in Arabic scholarly texts, this area is largely neglected in academic research. The present study examines the generic structure and the linguistic patterns of gratitude expressions used in acknowledegments accompanying the Arabic Ph.D. dissertation genre. To this end, I have analyzed the various rhetorical component options that writers use to convey gratitude and the role played by the socio-cultural factors in shaping this genre in a corpus of 100 Arabic acknowledgements accompanying Ph.D. dissertations in soft sciences written by doctoral Arabic native speakers. A discursive genre analysis reveals that Arab writers tend to use certain sociocultural specific components that can be seen as contextualization cues bringing about the religious beliefs, and the academic and social conventions of the Arab writers. Further, they tend to utilize certain preferred address forms, and social honorifics together with various gratitude expression options having different degree of intensification to respond to different types of audience and reflect their complex relationships with the academic and social community members.
\end{abstract}

Keywords: Genre; Arabic dissertations; Acknowledgements; Socio-cultural motivations.

\section{Introduction}

There has been a growing interest in the rhetorical features of academic writing, expanding the focus of study and interest beyond the primary genres (e.g. research articles, journal abstracts, books, dissertations, etc.) to the institutional or occluded genres (Swales 2004: 18) such as research grant proposals, evaluation promotion letters, referees' review of books or articles, and editorial correspondence. A dissertation acknowledgement, defined by (Hyland 2003: 243) as a 'Cinderella' genre which is

1 Transliteration: The most noteworthy symbols used in transcribing Arabic words given in this article are: $?$ glottal stop, $q$ voiceless uvular stop, $g$ voicd velar stop, $d$ emphatic voiced alveolar stop, $\partial$ emphatic voiced alveolar fricative, $\partial$ voiced interdental fricative, $\theta$ voiceless interdental fricative, $j$ voiced post-alveolar affricate, $y$ palatal glide, $\int$ voiceless alveolar fricative $t$ voiceless dental emphatic stop, $s$ voiceless alveolar emphatic fricative, $h$ voiceless glottal fricative, $\hbar$ voiceless pharyngeal fricative, $x$ voiceless uvular fricative, $\delta$ voiced uvular fricative, $S$ voiced pharyngeal fricative, $a$ short central low vowel, $a$ a long central low vowel, $u$ short back high vowel, $u u$ long back high vowel, $i$ short front high vowel, and $i$ long front high vowel. 
'neither strictly academic nor entirely personal', seems to belong to the institutional group, however, constituting a peculiar genre of its own. The writers of these genres have attempted to produce texts that plausibly reflect interaction with different audiences in terms of exchange of materials, information, support, and advice. Taking genre analysis as the study of how language is used in a particular socio-cultural context, the attention of texts' analysts has therefore turned to examining the textual and generic organization components as well as the socio-cultural interactive features that writers draw on to engage their audience to establish and maintain a successful writerreader relationship. However, one genre through which writers explicitly negotiate interpersonal relationship and reflect socio-cultural interactions that has received little attention in the research literature is dissertation acknowledgement, particularly those written in Arabic. One reason for this neglect is perhaps the perception that this section, unlike any of the main component sections of the dissertation, does not form an instrumental construction to the dissertation's rhetorical epistemology and stands outside the research record of establishing academic issues due to the assumption that acknowledgements along with prefaces, illustrations and dedications belong to the 'paratext' category (Genette 1997 [quoted in Giannoni 2002: 3]).

Thus this study is an attempt to analyze the language used in Ph.D. dissertation acknowledgements written in Arabic by graduate Arabic native speakers. These texts will be analyzed at two broad levels: Firstly, their generic component structure representing the strategic choices which reflect how the writer manages his relations to the audience; and secondly, the lexico-grammatical features used to express these strategic component options.

\section{Acknowledgement genre as an academic practice}

The acknowledgement genre is a notable practice in academic research (e.g. dissertations, books and research articles). According to Brodkey (1987), acknowledgements are 'formal properties of scholarly texts' (p.18), and are part of 'the cultural repertoire of all academics' (p. 23). In his study of experimental reports in physics, Bazerman (1984: 182-183) notes that acknowledgements date back to 1890s; they 'were personal testimonials to friends and mentors' whereas those that re-emerged in the 1920s 'were more spare, sharing limited forms of credit and recognizing institutional dependencies'. However, he points out that acknowledgement sections did not explicitly emerge until 1940 and were not a regular feature of Physical Review articles until 1960. Likewise, Mackintosh (1972 [quoted in Cronin 1995: 47]) found that the frequency of occurrence of acknowledgements in the American Sociological Review journal was $19 \%$ in 1940 , whereas it rose to 62 percent as this practice has become normative by 1965 .

The main communicative function of this genre is to textualize gift giving for all kinds of contributions received from others to accomplish a piece of academic research. Acknowledgements, as Cronin (1995: 14) notes, are meant to express gratitude that reflects a mix of personal, moral, financial, technical, intellectual and conceptual support provided by or received from institutions, agencies, peers, mentors, academics, family members, and experimental subjects. For Swales and Feak (1994: 203), the acknowledgement section is not only a display of gratitude for assistance, but also an opportunity for acknowledgers to show that they are members of the academic 
community and have benefited from that membership. Hyland (2000: 20) points out that by acknowledging the debt of precedent, a writer is able to display an allegiance to a particular community and establish a credible writer ethos. In an analysis of 200 anthropological ethnographies, Ben-Ari (1987) describes acknowledgements as 'special textual constructs' whose 'formation is governed by conventions which are different from those of the main text' (p.79). Overall, the author sees acknowledgements as

formulations that take on an intermediate position between the internal contents of the ethnography and the people and relationships outside it: They are both an introduction to an intellectual product and a reconstruction of the external contributions that have gone towards its realization. (p. 65)

To my knowledge, there is no study that has focused on Arabic acknowledgement practice. Thus, it will be necessary to consider what has been found in other languages such as English in which this practice is well-established and has been of great interest to both bibliometrcians and genre analysts. Bibliometricians have tended to focus almost exclusively on research article acknowledgement typology in the form of models of functional categories describing the kind of assistance received from others (see Mackintosh 1972; McCain 1991; Cronin 1991). However, these researchers have not attempted any form of detailed investigation of the organizational patterns and their linguistic realization in any particular genre.

The studies related to genre analysis of acknowledgement sections (Giannoni 2002; Hyland 2003, 2004; Hyland and Tse 2004) have focused on the schematic organization components and the linguistic features used to realize the component patterns in the acknowledgement section texts. In a discursive contrastive analysis of English and Italian acknowledgements in research articles, Giannoni (2002) demonstrates the socio-rhetorical and cultural generic variations such as generic staging, peer reference, pragmatic appropriacy and authorial responsibility that shape the rhetorical preferences of the English and Italian writers. Hyland (2003 and 2004) on the hand examined the English dissertation acknowledgement sections written by nonnative speakers of English. Both studies conclude that this type of genre is a complex construct that offers students the opportunity not only to thank those who have shaped the dissertation texts but also to textualize and promote the social, professional, and personal identity of the writers themselves. Hyland demonstrates that instances of the same acknowledgement data consist of a three tier structure: (i) Reflecting Move, (ii) Announcing Move, and (iii) Thanking Move, which is in turn divided into the following sub-units: Presenting participants, Thanking for academic assistance, Thanking for resources, and Thanking for moral support. In a subsequent study of the same acknowledgement texts, Hyland and Tse (2004) identify the linguistic patterns employed by acknowledgement writers to express thanks.

The conclusions which emerge from these studies are: First, despite the fact that bibliometric and genre analysis studies have examined academic acknowledgements, both types of studies differ fundamentally in focus and consequently in methodology. In particular, none of the bibliometric studies has offered a systematic description of the linguistic features of acknowledgements to support their models. Second, although Giannoni's (2002) analysis has addressed this gap, his analysis was restricted to the features of acknowledgements in research articles. Third, while all of these researchers have shed light on how English acknowledgers articulate their gratitude, little is known 
of the ways other language groups express their thanks (Hyland and Tse 2004: 274). Finally, although the acknowledgement section is a crucial element in Ph.D. theses written in other languages, such as Arabic, to the best of my knowledge, no study of which I am aware has been carried out to identify what generic component options are common in a variety of Arabic acknowledgements written by Arabic native speakers, and what linguistic expressions are used to realize these components, Therefore the present study is an attempt to fill these lacunae.

\section{Corpus construction and procedures}

A total of 100 acknowledgement sections written in Arabic by doctoral Arabic native speakers were selected for the present study. To minimize variations across disciplinary boundaries, the sample was restricted to acknowledgement sections covered humanities and social sciences (Arabic Linguistics, Arabic Literature, Education, Psychology, Sociology, Political Sciences, Geography, Religion, Management and Marketing, and Islamic Studies). Ten acknowledgement sections were analysed from each of these ten academic disciplines. The length of the texts ranges from 74 to 784 words. The average was 216 words. The sections were written in Arabic by Arabic native speakers from Jordan. I have focused on 'soft knowledge' domains due to the dearth of Arabic Ph.D. dissertations written in the hard sciences in the Arab Universities as most of the Ph.D. holders in the hard sciences graduate from Western universities. The other reason for the focus on these disciplines is to consider Arabic written acknowledgements that rely on localized input. To control rapid changes within any of the disciplines, the texts were selected from dissertations written over a period of nineteen years (1985 to 2004). Extracts were taken from this set of dissertation sections omitting the writers' names or any element that revealed anything about the identity of the people concerned.

\section{The socio-cultural context of the study}

To have a clear conception of the nature of gratitude and thankfulness in Arabic dissertation acknowledgements, I need to shed some light on the broader socio-cultural context of thankfulness and gratitude as a communicative event. Fairclough (1995: 11229) emphasizes the centrality of the situational context by looking at issues related to the place of production of the text and the socio-cultural factors that go into producing and interpreting it. As the genre texts under analysis are produced and interpreted in relation to their cultural context, it is necessary to define culture. There are many definitions for culture because it can be conceptualized and defined from various perspectives. For instance, Samovar and Porter (1994) define culture as:

The deposit of knowledge, experience, beliefs, values, attitudes, hierarchies, religions, roles, [...], and material objects, and possessions acquired by a group of people in the course of generations through individual and group striving. (p.11)

The cultural values, which are defined by Samovar and Porter (1994) as 'a set of organized rules for making choices...' (p. 15), specify and even constrain how members behave and interact in particular communicative contexts. 
As the texts are produced by Jordanian Arab writers, it is supposed that the writers' cultural values and the socio-cultural context are complexly woven into the ideology presented in these texts. In this way, these socio-cultural factors are essential in understanding the writers' communicative purposes as they manifest their effects on the content choice and schematic structure of the texts, which are constructed in these situations (Kress 1989: 19). Therefore, the texts produced by the Jordanian Arab writers are assumed to be influenced by Arab culture-specific conceptual categories that include, among others, religious affiliations and beliefs, social customs and hierarchy, as well as commitments related to family, relatives and friends.

Regarding religious affiliations, the vast majority (95\%) in Jordan is Moslem and Arabic speaking. The overwhelming majority of Jordanians' practices are governed by Islamic prescriptions (Al-Ali 2006: 694). In this regard, Harries (1958: 40) points out that 'Islamic law embraces the whole range of personal and social life' in Jordan. Despite regional differences in the religious specifics of adherents, Islam provides a framework within which Arabs from different parts of the Arab world tend to identify themselves as one people (Harris 1958). Although the Jordanian writers have an Arab identity, they turned to the concept of a wider religious belonging; they have assimilated an Islamic religious identity with an Arab as an ethnic identity. According to Watt (1987 [quoted in Faruqi 2005: 17]), ethnic and religious identity can be assimilated in the case of Islam. Thus it is likely to argue that Islamic religion is one of the basic features of culture that has influence on the Arab socio-cultural practices. Their social life, as Castleton (2006: 76) points out, is generally regulated by religious percepts to the extent that social values are largely indistinguishable from religious values and practicing a communicative event tends to be derived from an inner need to satisfy religious beliefs.

The Jordanian Arab writers share a common heritage of Islamic values, amongst which are 'thanking' and 'paying gratitude'. Consequently, Islamic religion has prescribed a shared body of values and convictions for conduct related to paying gratitude that delineate and constrain the Arabs' faith. Gratitude, according to McAuliffe (2003), is a moral marker usually paid in response to kindness. It is 'a spiritual and moral state of mind, spiritual in the sense of acknowledging the believer's obligations to the creator, and moral in the sense of maintaining rightful conduct in relation to God and to those appointed by God [i.e. people]' (p. 370). Gratitude is an attribute of divinity due to the fact that the Holy Qur'an mentioned ninety-nine names and titles for Allah (i.e. the most beautiful names that belong to Allah), one of which is Paf-fakuur (meaning the All-Thankful). The verb fakara (meaning to thank, or to be grateful) and its various cognates such as $f u k r$ (meaning gratitude) occur seventy-five times in the Qur'an. For instance, Allah says: wa-llaahu fakuurun ћaliim 'Allah is AllThankful Most Forebearing' [Q. 64: 17]. Besides, within the names of Allah and embedded in their use is the belief that Allah deserves intense and frequently expressed acknowledgement along with appropriate honorifics (Castleton 2006: 72). The sayings of Prophet Mohammad came to disseminate gratitude within the Arabic culture. He promotes gratitude to both Allah and people as he says laa yajkuru Allaaha man laa yafkuru nnaas 'he who does not thank people does not thank Allah'. As related by AlJawziyya (2000: 175), wa-qeel: Riðaa qasurat yaduka San al-mukaafiah falyatul 
lisaanuka bi-f-fukr (It was said: 'If you cannot offer recompense, you should offer thanks').

While the Holy Qur'anic prescriptions and the prophetic sayings played a seminal role in promoting thankfulness to Allah and parents, the social customs and traditions, as well as commitments related to family, relatives and friends also helped to support and disseminate gratitude. The Arab society has developed a set of shared understandings, modes of actions that provide overarching principles for Arab interaction considered appropriate for the individual needs and the desired ends the society sets for its members. This type of cultural grammar includes aspects of relationships between members of the Arab society related to a system of rights, duties and favors in the form of behavior expressions realized in offering help, or services initiated and exchanged between persons. These kinds of help in turn normally set up obligations: the favored person has the duty to return the favor with something of equal value or preferably of a little greater value. In the case of Ph.D. dissertation writers, there are individuals who either do favors or have the duty to fulfill obligations for the writers. These individuals include, besides others, supervisors, other academics, wife, husband, parents, relatives and friends. To illustrate, academic supervisors have a duty to supervise the thesis, provide critical feedback, and shape the reported work through their ideas and insights. This is considered by the supervisees as a favor which in turn elicits an obligation from them in the form of thanking and paying gratitude. In other words the supervisors and other academics are entitled to certain duties from their supervisees. Mutual obligations and favors are also demanded of those with kinship ties to the writers, such as parents, wives, husbands, brothers and sisters since the Jordanian culture could be termed as 'a kinship culture' (Al-Ali 2006: 707). Brothers are expected to be supportive morally. Therefore, one can say that there is a kind of 'corporateness' between the family members as they see themselves in relation to others, as members of groups (i.e. extended family), and are expected to sacrifice their own needs for the greater good of the group. Because it is thought that the individual achievement of the favored person is for the benefit of the family members (Rugh 1985: 278-9).

\section{Theoretical framework and procedures of data analysis}

To identify the genre component options available to Ph.D. acknowledgement writers that are used to articulate the communicative purposes of the dissertation acknowledgement texts and the socio-cultural forces that give explanations for these generic resources and the lexico-grammatical devices used to realize these options, I employed Bhatia's (2004) notion of genre which considers a genre text as a sociocultural practice. Since no research, as far as I know, has been carried out on acknowledgement genre in Arabic texts to offer a grounded language identification and description of the acknowledgement genre component options and their lexicogrammatical textualization, I utilized Hyland's (2004) coding scheme for a corpus of English dissertation acknowledgements written by graduate students, with modifications and additions of certain moves. Hyland's analysis is based on Swalsean (1990) genre moves for article introductions which has been profitably extended by genre analysts to other academic genres. Genre analysis has been approached from different perspectives. Whether approached in terms of the existence and arrangement of obligatory and optional structural elements (Halliday and Hasan 1989: 63-4), or recognizable 
communicative events characterized by a set of consistent communicative purposes (Swales 1990: 58; Bhatia 1993: 13), or typification of rhetorical actions (Miller 1984: 151; Bazerman 1994: 315- 16), or regularities of staged, purposive social processes (Martin 1992: 505), genre theory covers a lot of common ground (Bhatia 2004: 22). Despite these seemingly different perspectives stimulated by different orientations, genre analysts study genre as a communicative linguistic behaviour in a particular setting. It is characterized by identifiable communicative purposes that shape the schematic move options used by writers to construct the genre. Table 1 below provides a description of the modified coding scheme. The addtitions and modifications of Hyland's coding schem include the addition of five moves: 'Opening', 'Thanking Allah (God)', 'Invoking and Blessing', 'Closing' and 'Signing off'. Examples from actual acknowledgement texts of each of the genre moves identified together with their English translations are given in Section 6.

All of the acknowledgement texts were first electronically scanned and converted to computer text files. Each of the texts was then coded for the generic moves by the researcher himself. After discussing and presenting a defintion of each move, I asked another trained linguist to code a sample of thirty texts. On a check of inter-rater reliability, the two raters had an agreement rate of $91 \%$ in idntifying and categorizing the moves on 30 (30\%) selected acknowledgements. Quantitative analysis of linguistic features and their frequencies within moves was then performed. The component moves which appeared most frequently in my analysis of graduate student acknowledgements are listed in Table 1.

I also investigated the role of the socio-cultural perspectives that contribute to the construction and interpretation of this discourse genre. These perspectives cover a range of features such as beliefs, norms and conventions, which in turn give rise to the unstated behavioural principles (Bhatia 2004: 25) on the part of the members of a particular academic or professional group when they participate in social or academic communicative events. According to Bhatia (2004: 20), the emphasis at this level of analysis tended to extend the analysis beyond the textual product to include the broad socio-cultural context to account for the way text is constructed and often interpreted, used, and exploited in specific institutional or academic contexts to achieve particular communicative purposes.

\section{Generic structural features of Arabic acknowledgements}

Genre analysis is used here to find out the component rhetorical moves and the lexicogrammatical devices graduate students utilize to construct an acknowledgement text. The analysis of the generic structure of Arabic Acknowledgements accompanying Ph.D. dissertations has shown eight-move components (see Table 1). The texts analyzed demonstrated differences in the number and frequency of moves employed, as well as the type of component moves included. In the corpora analyzed, the moves higher up the list usually made their first appearance before those lower down. There were, however, some exceptions. Move 5, 'Thanking for Moral Support', sometimes, occurred before Move 4, 'Acknowledging Access to Resources', and Move six, 'Invoking and Blessing' tended to appear immediately after the thanking moves 3, 4, 5. 


\begin{tabular}{|l|l|}
\hline Component Moves of Arabic Acknowledgements, $\mathrm{n}=100$ & $\begin{array}{l}\text { No. of } \\
\text { Moves }\end{array}$ \\
\hline 1. Opening & 25 \\
2. Praising and Thanking Allah (God) & 70 \\
3. Thanking Supervisor(s) and other Academics & 100 \\
4. Acknowledging Access to Resources & 62 \\
5. Thanking for Moral Support & 61 \\
6. Invoking and Blessing & 68 \\
7. Closing & 52 \\
8. Signing off & 20 \\
\hline
\end{tabular}

Table 1. Number of Move Components for Arab Dissertation Acknowledgements

I now present the individual components of the acknowledgement genre found in the corpora with illustrative examples. The frequency of each component and the order in which these individual components occur are given in Table 1. The English interpretation of the exemplatory Qur'anic verses, which are related to the component moves, is taken from Ali's (1989) translation of the Holy Qur'an.

\subsection{Opening}

The first component of the Arabic acknowledgements examined was the 'Opening'. It occurred in 25 percent of the sample. This component opens with one of the following options as is shown in Table 2:

\begin{tabular}{|l|l|}
\hline Opening Option & Frequency \\
\hline Qur'anic verse & $8 \%$ \\
\hline Prophetic saying & $5 \%$ \\
\hline Prayers on the Prophet & $6 \%$ \\
\hline $\begin{array}{l}\text { Invocation followed by the formulary } \\
\text { expression wa-baid (and then) }\end{array}$ & $6 \%$ \\
\hline Total & $25 \%$ \\
\hline
\end{tabular}

Table 2: Distribution of Opening Options across Corpus

a) A Holy Qur'anic verse: Either of the following Qur'anic extracted verses exemplifies the kind of the realization available in the corpus:

1. wa-laqad Paataynaa Luqmaanal-hikmata Pan ifkur li-llaah wa-man yajkur fa Rinnamaa yajkuru li-nafsih [Q.31: 12]

(We bestowed wisdom on Luqmaan: "Show (thy) gratitude to Allah." Any who is (so) grateful does so to the profit of his own soul.) (Ali 1989: 1036)

2. Pal-hamdu li-llaahi l-laðii hadaanaa li-haaðaa: wa-maa kunnaa li-nahtadiya lawlaaa Pan hadaana Allaah [Q.7: 43] 
(Praise be to Allah, Who hath guided us to this (felicity): never could we have found guidance, had it not been for the guidance of Allah.) (Ali 1989: 355)

b) A Prophetic saying: Following the guidance of Prophet Mohammed who encourages man to express thanks, few writers begin this genre by including the following Prophetic saying as an opening component:

3. laa yafkuru l-llaaha man laa yafkuru n-naas (he who does not thank Allah does not than people).

c) Prayers on the Prophet: Another conventional opening that makes a frequent appearance and habitually followed to initiate acknowledgements is Pal-hamdu li-llaahi was-salaatu Sala rasuuli llaahi Moћammed (Praise be to Allah, prayers and peace be on Mohammed the Prophet of Allah).

d) A form of invocation realized by the following verse from the Holy Qur'an, followed by the formulary expression wa-baid 'and then':

4. bismi llaahi r-raћmaani r-raћiim 'In the name of Allah, Most Gracious, Most Merciful' [Q.1: 1].

The fourth option is a convention found not only in acknowledgements' openings but also in the openings of many Arabic communicative events. It is also used as a formula printed at the top of business letterheads as it is a typical header for books, letters, wills, legal documents etc. Muslims in general place their hope in the mercy of Allah; therefore, the expression 'In the name of Allah' is recited or written prior to commencing any action (Al-Ali 2004: 17).

\subsection{Praising and thanking Allah}

This component occurred in 70 percent of the Arabic acknowledgements analyzed. When employed, it generally occupies the first position in comparison to other thanking component options. This component contains expressions of gratitude, and praise to Allah (God) for His favors; one of these bounties is making the completion of the Ph.D. dissertation task possible. The expressions Pal-ћamdu li-llaah 'Praise be to Allah', and Paf-fukru li-llaah 'Thanks be to Allah' or a combination of both are prevalent in the corpus. The corpus revealed that the praising expressions are more prevalent than those of gratitude and are given prominence when both are mentioned together in the corpus. Praising Allah phrases occurred in 35 percent of the acknowledgements sampled whereas expressions of gratitude to Allah were found in 15 percent. 


\begin{tabular}{|l|l|}
\hline Expression Type & Frequency \\
\hline Praising phrases & $35 \%$ \\
\hline Thanking phrases & $15 \%$ \\
\hline Praising followed by Thanking phrases & $20 \%$ \\
\hline Total & $70 \%$ \\
\hline
\end{tabular}

Table 3: Expressions of Praising and Thanking Allah

The sample also yielded 20 instances in which the expressions of 'praise to Allah' are accompanied by others of 'gratitude'. However, praise expressions usually appear in the front position when both variants, 'praise' and 'gratitude, are given. The following examples illustrate these three variants, respectively:

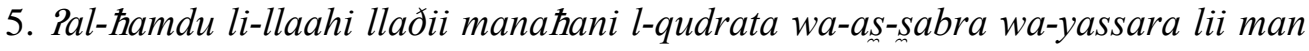
Panaara tariiqii wa-zawaddanii bi-n-nushi wa-l-Pirrfaadi li-Ritmaami haadihi rrisaalah.

'Praise be to Allah who endowed me with strength and patience and made available to me those people who advised and guided me to complete this thesis.'

6. Paf-fukru Pawalan wa-Paxiiran li-llaahi l-Sadiim Pallaðii waffaqanii li-Pinjjaaz haaða al-Samal

'Thankfulness first and last for Allah, the Glorious, who guided me to complete this work.'

7. Pal-hamdu li-llaahi l-mutafadil Salayya bi-ni Samihi l-latii laa tu Saddu wa-laa

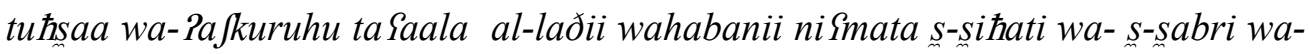
lmuAaabarah

'Praise be to Allah for his numerous and countless bounties and I thank Him who endowed me the graces of health, patience, and perseverance.'

\subsection{Thanking supervisors and other academics}

The aim of this component is to pay off one's intellectual debts to individuals who have made significant intellectual influence and contributions of various kinds such as originating the idea of the thesis, shaping the reported work through their ideas and insights, or providing critical feedback. Further, it reflects a rich mix of personal, moral, intellectual stimulation provided by intellectual, and conceptual support received from members of the discourse community (i.e. principle dissertation advisors, doctoral committee members, senior academics, and instructors). This component registers personal and 'behind-the-scenes' interactions. It also gives insights into the values and attitudes of the discourse community and the relationship between the individual and the world of academia. Since this component is the only step that has been found in all texts, it can be considered an obligatory constituent.

The corpus data showed that the acknowledgers tend to exploit elaborate and deferential patterns of thanks and gratitude expressions especially to their supervisors. 
They utilize overt forms of thanks expressed mainly through nominalization, or a performative act to realize this component as shown in Table 4.

\begin{tabular}{|l|l|l|}
\hline Form & occurrences & $\begin{array}{l}\text { Frequency of } \\
\text { occurrence }\end{array}$ \\
\hline I. nominalization & 307 & $85 \%$ \\
1. Conjoined synonyms other than 'thanks' & 92 & $30 \%$ \\
2. 'Thanks' conjoined with other synonyms & 215 & $70 \%$ \\
\hline II. performative verbs & 46 & $15 \%$ \\
\hline Total & 353 & $100 \%$ \\
\hline
\end{tabular}

Table 4: Patterns Expressing ‘Thanking Supervisors and Other Academics’

The Ph.D. students relied heavily on nominalized forms (85\%) as a main option of expressing thanks followed by the verbal forms (15\%). There was a strong preference for the noun $f u k r$ 'thanks', and other related near synonymous nouns such as Rimtinaan 'gratitude’, taqdiir 'appreciation', Sirfaan 'admission', Pikbaar 'glorification', Oanaa? 'praise', Rijlaal 'exaltation', fadl 'favor', and Ritiraam 'reverence' usually with an introductory preface, and for the performative verb Pafkuru 'I thank'. The acknowledgements also showed that the noun fukr 'thanks' and the other related synonyms were more likely to be accompanied by premodifying and/or postmodifying adjectives to intensify the extent of thanks (example 8). A range of 54 different adjectives were used to amplify these nouns. Moreover, there was a marked preference for a few premodifying adjectives such as jaziil 'immense', Gað̈iim 'massive', xaalis 'sincere', Paћћarr 'warmer', Pajmal 'more beautiful', or xaas 'special', and other few post modifying adjectives such as jaziil, Samiiq, and mawsuul 'endless'. Moreover, the nominalized forms of thanks and gratitude were further intensified through extensive use (70 percent of the cases) of the noun $\int u k r$ conjoined with one, or more of the other synonymous nouns Rimtinaan 'gratitude', taqdiir 'appreciation', Sirfaan 'admission', Rikbaar 'glorification', Oanaa? 'praise', Rijlaal 'exaltation', appended to its left. Similarly, thirty percent of the nominalized acts of thanks in the corpus were realized by a combination of two synonymous nouns other than $f u k r$ such as Ritiraam wa-taqdiir (reverence and appreciation), and Rimtinaan wa-Aanaa? 'gratitude and praise'. It is worthwhile noting that these appended and modified nominal forms of thanks are usually reserved to supervisors.

\section{Pawaddu Pan Ruqadima jaziila wa-xalisa af-fukri wat-taqdiir wa-Sadiimi l-} imtinaani l-mawsuuli Rilaa mufrifii (...).

'I would like to pay immense and sincere thanks and appreciation and endless and massive gratitude to my supervisor (...).'

It is obvious that the thanks offered to academic supervisors are exaggerated as the acknowledgers tend to exploit elaborate deferential patterns of gratitude which are 
realized by synonymous nouns related to thanks such as 'admission', 'glorification', 'praise', 'exaltation', 'reverence'. These nouns are heavily intensified by pre and/or post modifying adjectives (i.e. immense, massive, sincere, warmer, and endless) to express the degree of gratitude to their supervisors.

Even though the responsibility of the professors is to offer guidance to the supervisees, the acknowledgers consider this a kind of favor which in turn elicits esteem and loyalty to their academics because the academic relationship binding them cannot be materially rewarded. This can be explained with reference to the cultural and linguistic tradition that enhances the master- student relationship. Some of the general and prominent sayings that reflect the Arabic traditions are: man Salamanii harfan kuntu lahuu Sabdan (One is always enslaved to the person who has taught him), and PalSulamaa $\mathrm{R}$ waraOatu al-Panbiyaa? (The scientists are the inheritors of prophets).

While thanks were usually expressed in this way, in 15 percent of the cases, the writers employed the simple verb Pafkuru 'I thank' when they offered their thanks to the members of the examining committee, sometimes, accompanied by introductory phrases. In such cases, the act of thanks was preceded by a preface realized by modals and mental state verbs 'I would like' (example 9), or modals expressing obligation (example 10) to premodify the main thanking verb.

\section{Pawaddu Pan PaJkura Pa Sdaa Plajnati l-munaaqafah}

'I would like to thank the examining committee members.'

\section{0. yajibu Pan Pafkura al-mufrifiin Salaa haaðihi r-risaalah}

'I must thank the supervisors of this dissertation.'

There also appeared that the acknowledgers in the examined corpus introduced their supervisors and academics with their titles (Doctor, Professor Doctor) followed by their names, positions and professional memberships if they have any. In addition, it was noticed that some academics (20\%) in the corpus, especially supervisors, were referred to using address forms borrowed from kinship terms like Pab 'father' for endearment and deference purposes. None at all were mentioned without a title. Other absolute social honorifics such as feix 'sheikh', mu Sallim 'teacher', and murabbyi 'mentor' were also used in addressing the supervisors. The following excerpts from the corpus illustrate this:

11. wa-laa yafuntunii Pan Pafkura mufrifii Pal-Pustaaða d-duktuur (XX) Pallaðii Saraftuhuu ka-Pabin haannin wa-murabbin faadil

'And I do not want to miss this opportunity to thank my supervisor Professor Doctor (...) whom I have known as a compassionate father, and an honorable mentor.' 


\subsection{Acknowledging access to resources}

This component includes thanks and gratitude addressed to participant subjects and those who avail or provide access to data, technical assistance, clerical help (e.g. proofreading, typing, and statistical analysis), financial support, or facilities that are necessary for the academic study. This step occurred in 62 percent of the acknowledgements analyzed and generally followed component 3. To repay some of the assistance received to accomplish their degrees, dissertation writers tend to use overt expressions of thanks which involve either a bare performative verb Pajkuru 'I thank' without an introductory preface, which accounted for $40 \%$ of all forms (example 12) or its simple nominalization fukran 'thanks' (45\%) (example 13):

12. Pa Jkuru jamii Sa l-Saamiliin fii maktabati jaamiSati l-yarmouk li-tazwiidii fii maa yalzamu min al-kutub

'I thank all the employees at Yarmouk Library for providing me with the necessary books'.

13. wa-f-fukru Paydan Rillaa al-Puxt (X) Salaa tibaaSati r-riysaalati wa-Pillaa Paxii (Z) Salaa muraaja Satihaa

'And thanks are also due to sister (X) for typing the thesis and for my brother $(\mathrm{Z})$ for proofreading.'

It is worth noting that address forms borrowed from kinship terms were also used in this component. Unlike the supervisors who were sometimes addressed by the kin term, 'father', those who availed access to resources were referred to using other kin terms such as Ruxt 'sister' and Pax 'brother' (example 13 above).

Despite its smaller percentage (5\%), sometimes the nominalized fukran 'thanks' is accompanied with either a synonymous thanking noun or two such as Pimtinaan 'gratitude', and taqdiir 'appreciation' supplemented by an adjective, like jaziil 'immense' to intensify the extent of the writer's gratitude; besides, absolute social honorifics are attached (example 14).

14. Puqaddimu jaziila fukrii wa-mtinaanii Pillaa ma Saalii waziiri t-tarbyyiah PalPustaað Pad-duktuur (X) li-samaahi lii wa-musaa Sadatihi fii Rikmaali diraasatii 'I offer my immense thanks and gratitude to his highness, the Minister of Education, professor Dr. (X), for giving me the permission and assistance to complete my study.'

This component reflects variation in the amount of gratitude communicated to contributors. For example when it happens that the acknowledgee has a high status or holds a high academic degree, his/her name is introduced by being cited with full position and using an honorific together with a series of synonymous nominalized forms of thanks to appease him/her (see example 14). On the other hand, a simple word of thanks or its verb form is employed to address peers, participating subjects and technicians or employees (see examples 12 and 13); such expressions accounted for 
more than three quarters of the patterns of gratitude expressions used to realize this component.

\subsection{Thanking for moral support}

This category collates expressions of feelings of gratitude for psychological, spiritual, and moral support, encouragement, patience and care received from family members, relatives, friends and colleagues during the period of study. In particular, the data analyzed showed that this category allows the writers to thank parents for their love, supplications and invoking; wife/husband for patience, sacrifice, love and care; children for patience; brothers, sisters and relatives for love and moral support; and friends for help, psychological support and hospitality.

The data revealed that commitment to the social community represented by the extended family (i.e. father, mother, brothers, and sisters), relatives and friends was evident in $61 \%$ of the texts analyzed. Virtually most of the moral support moves employed in the corpus contained at least a word of gratitude to one's parents who were mentioned before other members of the family. This high frequency can be explained with reference to religious affiliations as the first thing that Allah enjoins upon man is to show gratitude to Him and to one's parents. Allah says:

Pan ifkur lii wa-li-waalidayka Rillayya l-masiir [Q.31: 14].

(Show gratitude to Me and to thy parents: to Me is (thy final) goal). (Ali 1989: 1037).

Wife or husband and children tend to be mentioned following parents who were always given pre-eminence in hierarchy. The writers are also aware of their duty owed to their brothers and sisters expressed in the form of indebtedness; this in turn reflects a lateral kin relationship to brothers and sisters. The following example illustrates such relationships:

15. jaziilu f-fukri illaa Pumi il-habiibah wa-Pabi il-Saziiz li-duSaa Rihim lii waSaðiimi l-mtinaani Paydan Rillaa zawjatii as-saabirah allatii ra Sat Pawlaadii waPajkuru Pawlaadii li-taћamulihim wa-PaJkuru Rixwaanii wa-Paxawaatii wa-

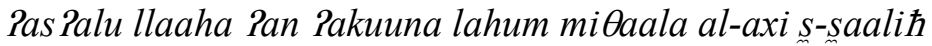

'Many thanks are due to my beloved mother and dearest father for their supplications and massive gratitude also for my patient wife who took care of my children, and my children for their endurance. I also thank my brothers and sisters and I invoke God to be a good model for them all.'

It is worthwhile noting that the act of thanking addressing parents and wife or husband were likely to reflect an 'intrinsic' (Hyland and Tse 2004: 269) commitment on the part of the writers. This tendency is evident in examples like (16) where the thanking act contains a preface including modals and mental state verbs to signal the writers' inclination toward the addressees. 
16. wa-Paraa lizzaaman Salayyia Pan Pafkura waaliddayyia l-ћabiibayin Salaa daSmihim al-maSnawiyy wa-zawjatii l-Saziizati llatii raafaqatnii fii riłlatya t- $^{-}$ tawiilah

'And I see that I must thank my beloved parents for their moral support and dearest wife who accompanied me during my long journey.'

However, the acts of thanks directed to brothers, relatives and friends were mostly encoded by a simple performative verb Pafkuru (I also thank my brothers and sisters...) (example 15 above) or its nominalization fukran 'thanks'.

\subsection{Invoking and blessing}

Another favoured strategy is invoking God's (Allah's) favors upon acknowledgees. This act includes requests of Allah's bestowal of divine favor on an addressee to protect and guard him/her from evil thereby bringing him/her happiness. Invoking and blessing are generally fulsome, often even lavish, virtually in this corpus; they occurred in over half of the acknowledgements analyzed. It is interesting, however, that this strategy carries explicit interpersonal connotations, similar to patterns of complimenting behavior at speech events, such as phatic conversation (Holemes 1995; and Wolfson 1989 [quoted in Hyland 2000: 53]). There were hundred and forty-five invocation acts in the 100 acknowledgement texts analyzed; all of these acts call upon Allah either to reward the acknowledgers; or to bless them; and/or to grant the addressees enjoyable good health and long living; to bless their lives, knowledge, work, and progeny; and to help them achieve more success and progress in their future research, especially when addressed to supervisors. However, neither of these invocations is arbitrary; they are part of their culture reflecting their realm of thought. 'It may seem obvious that words with special culture-specific meanings reflect and pass on not only ways of living characteristic of a given society but also ways of thinking' (Wierzbicka 1997: 5). The most frequent invoking act used to realize this strategy was the expression jazaaka Aallaahu xayran 'Allah will reward you well'. The writers relied heavily on this expression to express the Invocation and Blessing to the extent that it forms fifty-two percent of the invocation expressions utilized in the corpus. The high frequency of this particular expression could be attributed to the teachings of Prophet Mohammed who taught that 'When someone does you good and you say "Allah will reward you well" to the person, you have done the utmost in praise' (Tirmithi). In other way 'the greatest way to thank people is to call upon Allah to reward them' (Morrow 2006: 138). Other common expressions used by the writers cover invocations related to acknowledgees' survival and good health (22\%), God's blessing and support of the addressees' knowledge, and progeny $(10 \%)$ and to help them achieve more success and progress in their future research (8\%); another $8 \%$ of the occurrences of this strategy are realized by other invocation expressions calling upon Allah to save the acknowledgee as a carrier and disseminator of knowledge, and to bestow His blessings upon him/her and accommodate him/her in paradise in the hereafter with prophets and scientists.

A significant issue related to this strategy is the fact that more than 80 per cent of the writers who included this component chose this strategy to supplement the 
'Thanking Move', particularly thanking supervisors and academics. Further, this component does not occur only once in each individual acknowledgement genre. Most often the writers opted for a composite 'Thanking' followed by 'Invoking and Blessing'; this pattern is repeated several times. That is to say, when an acknowledgee is thanked, this act is often supplemented by invocations.

\subsection{Closing}

Instead of ending abruptly, about half of the writers (52\%) add a sentence or a few to conclude the whole text in order to give it a sense of completeness. This component is commonly marked by being set apart in the post-body position of the acknowledgement text. Twenty-six percent of these acknowledgements contain either praises for Allah (example 17), supplications to bless the writers and to bring them more success (example 18), or indicating humbleness (example 19). The following instances, respectively, exemplify these three kinds of realization available in the corpus, the first two of which are direct quotations from the Holy Qur'an whereas the third is based on a Qur'anic verse:

17. Pal-hamdu li-llaahi rabbi l-Saalamiin [Q.1: 2]

'Praise be to Allah, the Cherisher and Sustainer of the worlds' (Ali 1989: 14)

18. wa-maa Putiitum min al-Silmi Rillaa qaliilaa [Q.17: 85]

'Of knowledge it is only a little that is communicated to you, (O men!).' (Ali 1989: 698)

19. wa-Allaahu walliyyu t-tawfiiq 'And Allah is the source of success.'

Example 19 above has its roots in the following verse in the Holy Qur'an:

Wa-maa tawfiiqii Pillaa bi-llaah Salayhi tawakkaltu wa-Pillayhi Puniib [Q.11: 88]

'And my success (in my task) can come only from Allah. In Him I trust, and unto Him I look.' (Ali 1989: 535)

Another 18 percent of the acknowledgements were rounded off mainly by apologizing for not being able to list all or unwittingly omitting somebody who has significantly contributed to the accomplishment of this task. The other six percent of the acknowledgers dedicated their research for the sake of Allah and prayed that it may be used for the righteousness and benefit of all around them.

\subsection{Signing off}

It was found that forty percent of the writers claimed their ownership of the acknowledgement section by writing either the word Pal-baa hith (the researcher) (20\%), or the acknowledger's name only (8\%) or the word Pal-baa hith together with his/her name (12\%). It is worthwhile saying that the 'Signing off' component is also an epistolary convention in professional letter genre. 


\section{Discussion}

The preceding snapshot of the component strategies that are employed offers insights about Arabic dissertation acknowledgement genre with its discourse structures and the linguistic choices that tend to occur in this genre. In order to understand the rationale governing the rhetorical construction, which in turn reflects the communicative purpose of this genre, I turn now to discuss the socio-cultural values and academic constraints that give rise to both the template strategic potential components and the lexical choices available to the writers evidenced in this corpus.

\subsection{The lexical choice practices of gratitude expressions}

Since the thanking strategic components included in this genre are addressed to multiple audiences hardly a homogeneous grouping as this type of genre provides a valuable space for writers to present themselves as thankers to their God (Allah), and to members of their academic community, as well as to their family members, it is anticipated that the writers use appropriate patterns of gratitude expressions to handle and reflect these complex interpersonal relationships embedded in the different thanking moves addressed to different audiences. The regularities of lexical choices observed across these texts reveal not only a tendency on the part of the Arab writers to fall back on their socio-cultural norms but also a perception of how best to address and interact with their heterogeneous audience. For example, the thanking component 'Praising and Thanking Allah' contained a strong preference for the overt expression of praise, Pal-hamdu lillaah 'Praise be to Allah', which is only used when the writers offer their thankfulness for their God (Allah). Unlike the other expressions, which can be utilized to address all audiences, the selectional restrictions of this expression, Pal-ћamdu l-illaah, is governed by the religious convection that Allah is the only one who deserves this kind of praise. The corpus also revealed that the praising expressions for Allah not only are more prevalent than those of thanking but also are given prominence when both are mentioned together. According to Al-Jawziyya (2000: 176):

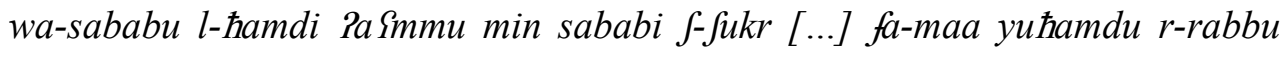
ta Saalaa Salyyhi PaSmmu mimaa yufkaru Salyyhi fa-Rinnahu yuћamdu Sala Pasmaa Pihi wa-sifaatihi wa-PafYaalihi wa-ni Samih wa-yufkaru Sala ni Samih

'The reasons for praising [Allah] are more general than the reasons for thankfulness. And what the Lord is praised for is more general than what He is thanked for. One praises Allah by His names, Attributes, Decrees and Gifts whereas he thanks Him only for His gifts.'

At the same time, one praises Allah with the wholehearted sense of joy without the anticipation of gifts while he thanks Him for His bounties. According to Castleton (2006), the high frequency of occurrence of praising and thanking Allah expressions is due to the fact that they are utilized extensively in the performance of daily communicative events. The frequent use of these expressions 'derives from reflections on and responses to Allah's influence over every aspect of human life' (p.76). Castleton 
further maintains that 'as a direct result of the deep connection they feel to their religion and creator, native Arabic speaking Muslims look at the events of daily life in terms of God's relationship to that event or interaction' (p.77).

Returning to the lexical options that are used to realize the other main thanking components including acknowledging supervisors and other academics, resources, and moral support received from family members and relatives, I found that the writers employed a range of expressions relying heavily on the performative verb, Pajkuru 'I thank' and its nominalized form fukran 'thanks' together with a series of synonymous conjoined nouns expressing thanks each of which is post modified by more than one adjective (see example 8). Utilizing different patterns of expressions and address forms here helps to demonstrate the complex interpersonal relationships of the acknowledgers with the academic and social communities, with which they are members and for whom they write; thus, there are differences regarding the degrees of intensification and the proportion of thanks of who is acknowledged. For instance, the data revealed that a great amount of appreciation was reserved to their supervisors. This was realized through an intensified range of different conjoined adjectives appended to nominalized conjoined synonymous nouns (example 8). On the other hand, the writers tend to use only a simple word of thanks realized nominally or verbally to address brothers, sisters, friends, technicians, subjects of the study, and those who provided access to data, and clerical help (see examples 12 and 13). However, the degree and amount of gratitude increases when it happens that the acknowledgee holds a higher status or an academic of professional degree (see example 14). This suggests that the writers are conscious of social and academic hierarchy (Giannoni 2002: 21).

The corpus also yielded interesting evidence regarding the use of different address forms and honorifics to respond to different types of audiences. The acknowledgers are typically willing to choose appropriate forms of address together with honorifics to signal the acknowledgee's status in order to indicate reverence or show awareness of the conventions of both the academic and the social communities they belong to. The choice adopted here is not only restricted to absolute ritualistic honorifics (Levinson 1983: 90-91) such as Doctor, Professor Doctor, Mr., Mrs., the Chair, His Highness but also includes relational social honorifics (Farghal 2002: 16364) borrowed from kinship terms that are originally used to designate family relations among relatives (e.g., Pab 'father', Pax 'brother', ?uxt 'sister', and Samm 'uncle'), but they are connotatively employed in this corpus for non-relatives to promote further purposes. For instance, the writers use the kin term, father, sometimes postmodified by another affectionate title of address like Pal-haanii 'compassionate or kindhearted' (see example 11) in addressing their supervisors; originally, such affectionate titles are indicative of high emotionality among intimates, as in the case of interaction between a mother and her child. Likewise, absolute honorifics such as feix 'sheikh', which is a title address originally reserved for either the head of a tribe or a state, is used in this context connotatively as a social honorific in addressing a male supervisor in a relational sense to promote him as a key figure and well-published academic in the area (e.g. feix Pallu yawiin meaning 'the father of linguists'). Thus, absolute honorifics of this sort have now acquired a relational sense since they are used for different purposes (Farghal and Shaker 1994: 247). However, with thanks for resources and material assistance, or for 
participating subjects, the writers tend to employ lateral kinship terms such as Pax 'brother' or ?uxt 'sister' for non-relatives to express a kind of endearment, expediency, and solidarity for the addressees (Boxer 2002: 132), or to avoid using the acknowledgee's first name only, which may sound direct. Likewise, Chinese utilize such terms not only for relatives, but also for non-relatives; however, terms of family relationships in English are only restricted for relatives (Lu 2009: 154).

By demonstrating the social meanings of the kin terms drawn on in this context, we understand the grammatical encodings of relative social and academic status between participants in the communicative event. In the realization of deference especially for supervisors, the acknowledgers tend to raise the acknowledgees to the position of senior members of one's family (e.g., father and uncle). This social etiquette, in turn, satisfies the acknowledgee's wants to be superior. However, when addressing individuals for access to data and resources, typically, occasional reciprocal deference occurs. It is achieved by lowering of oneself to the position of the subject participant who is addressed as 'brother'. It is worthwhile noting that the kinship terms 'brother' and 'sister', used in this context, can be explained with reference to Islamic traditions and socio-cultural practices that promote and enforce 'Muslim brotherhood'. This conception is one of the social ideals of Islam originally having its religious connotations in the Holy Qur'an (e.g., Rinnama l-muPminuuna Rixwah 'The believers are but a single brotherhood') [Q.49:10] (Ali 1989: 1341). Thus, the writers tend to exploit some linguistic resources from religious discourse to affirm the in-group identity and solidarity between the writers and the prospective addressees and reinforce shared values (Ferguson 1986: 205). This, in turn, supports Hyland's (2005: 13) view that the ways writers utilize in order to establish equal or hierarchical affiliation with their audience are constrained by the dominant ideologies.

Many recent studies have demonstrated that different languages communities tend to utilize different options to encode the social or the academic status between the participants. In non-Western cultures, such as Chinese, when one interacts with senior member of the family or authoritative senior persons, particularly teachers who assume knowledge and authority, the addressors use very formal address forms to denote seniority, such as the title or last name with a professional or academic title (Wong 2000: 152). Corresponding to this, Lee (2002) also finds a frequent use of an exaggerated formal address system in Chinese postgraduates' emails addressed to their instructors. The author suggests that the nature of exaggeration is a sign of respect for the role of teachers who are thought of as a symbol of authority and power in a hierarchy in the Chinese culture (p. 18). What contradicts this popular belief is that high status Japanese who hold high positions tend to use more elaborate higher honorific forms than those used by persons of lower status towards a person of higher status. The reason, according to Ide (2005: 61-2), is that the elaborate use of high honorifics indexes a metalinguistic meaning of dignity and elegance of the people who make habitual use of it. However, in Switzerland, titles in address are about to disappear. For example, 'a university professor may be addressed by his student orally or in writing as Herr Meier, with Herr Professor being rather exceptional' (Manno 2005:104). 


\subsection{Socio-cultural factors affecting the acknowledgement schematic components}

A discursive look at the generic components, which are ritually drawn upon in writing the acknolwedgement texts, displays some of the religious and socio-cultural motivations for the behavioral strategic choices to articulate the communicative purpose of this genre. For way of illustration, twenty-five instances of this genre were initiated with an 'Opening' based on Qur'anic verses or Prophetic sayings. Evidently, although this option does not have a high frequency of occurrence (25\%), it is in no means being considered arbitrary. The instances used to express this move seem to reflect the Qur'anic and Prophetic sayings, which focus on the centrality of praise and thankfulness to Allah (God). The centrality of the concept of Allah is fully fledged and reflected in the 'Thanking Allah' component, where seventy percent of the writers present their thankfulness and gratitude to Allah. The examples related to this strategic option show that the writers tend to contemplate Allah's right of praise and gratitude upon them because Allah is thought the source of inspiration, health, patience, perseverance and strength. According to the Qur'anic prescriptions, thanking and praising Allah for his munificence result in increasing the graces of Allah and getting very close to His mercy.

\section{la Pin Sakartum la-Paziidannakum wa-la Pin kafartum Pinna Saðaabii la-fadiid [Q.14: 7] \\ 'If you are grateful, I [your Lord] will add more (favors) unto you; but if you show ingratitude, truly My punishment is terrible indeed.'(Ali 1989: 605)}

Religious affiliation is further reinforced by the sixth component, 'Invoking and Blessing'. Calling upon Allah to bless the acknowledgees, the writers usually employ invocations to supplement the thanking components addressed to their supervisors (i.e. Move 3), and to those who were of help in access to data (i.e. Move 4). That is to say, the acknowledgers do not only employ thanking and gratitude acts, but these acts are also often supplemented by invocations. Cycles of this pattern including Component 3 or 4 followed by invoking and blessing element reoccur. Such cyclicity could be explained with reference to the cultural belief that 'the word of thanks by itself is not usually a sufficient response to an Arabic compliment and needs to be complemented by additional words' (Nelson et al. 1996: 429). This behavior also comes out in the 'Closing' (Move 7), where it is expressed by a sentence or a stretch of sentences having roots in the Holy Qur'an containing either supplications and/or praises for Allah to bless the writers and to bring them more success. Therefore these strategic components in this paper can be seen as contextualization cues that bring about the impact of religious beliefs and values of the writers.

Acknowledgement texts also furnish indications about the social system of favors and obligations constraining the acknowledgement behavior of the writers. For instance, in the 'Thanking for Moral Support' Move, the writers thank their wives for supporting and serving the daily nurturing of their family while their husbands are being heavily engaged in preparing their theses. That is to say, the wife is acknowledged for giving up her rights to provide a good image of herself and her family. In Arab's interdependent or collectivistic culture such as the culture in this study, where in-groups take precedence over individual (Triandis 1983 [quoted in Swangboonsatic 2006: 64]), family members see their happiness as resting in the realization of certain corporate purposes: in experiencing a satisfying family, and in exerting efforts to strengthen and 
coalesce family ties. Likewise, the system of favors and obligations sets up a kind of moral obligation on the Arab family members who have affective kinship ties to the writers, such as parents, brothers and sisters to support the Ph.D. writers by supplications and invoking, as well as financial support which is returned in the form of thanking and paying gratitude. Thus, one can claim that there is a kind of 'corporateness' between the family members, seeing themselves as members of an ingroup (i.e. extended family) who are expected to sacrifice their own needs for the greater good of the group. That is because the in-group thinks that the individual achievement of the acknowledged person is for the benefit of the group. Similarly, Mursy and Wilson (2001: 138) point out that Arab Egyptian society, 'which basically derives its values from Islam, elevates the group above the individual and values responsibilities and obligations towards the community'. However, while the Arab social ideology values cooperateness, and sacrifice to fulfill the extended family's goals, a fundamental truth for Westerners is associated with individualism, equal rights and the chances to realize individual goals (Rugh 1985: 276-77).

In contrast to Western view, the nature of the interaction and social relationships practiced by the graduate students seems to show similarity with non-Western way of viewing interpersonal relations in which politeness functions at the level of society rather than at the level of individuals. For instance, Gu (1990) indicates that politeness, in Chinese culture, is 'a phenomenon belonging to the level of society which endorses its normative constraints on each individual' (p. 242). Accordingly, individuals behave in conformity with culturally expected norms that are institutionalized by the society. That is to say they place the society's face above their individual desires. As pointed out by Foley (1997), Chinese can be characterized as sociocentric. In such cultures 'the individual and his autonomy are not singled out as the local understanding of person; rather his embeddeness in the social context is the stuff of this definition as a person' (p. 266).

If a comparison is drawn between the results obtained from analyzing the generic structure of Arabic acknowledgements and those reported in Hyland's (2004) study of Ph.D. dissertation acknowledgements, one can claim that there are differences as well as similarities. There are general similarities in schematic component moves with respect to the thanking moves (Thanking supervisors, and Thanking for data access, clerical and technical support, and for moral support). Thus, it might be argued that the use of these generic components (i.e. Hyland's model) in the Arabic texts may give an impression of the influence of the Western practice which might have been imitated by the acknowledgers who either have been taught by instructors having been influenced by the Western practice, or having had an idea about acknowledgements written by Western writers. Another explanation is that both Arabic and English acknowledgement data share general communicative purpose (i.e. acknowledging credit to anyone who has helped in any way) which is, in turn, articulated by these similar thanking generic moves. Related to this justification is that academic genres, to a certain extent, transcend the territorial constrains of ethno-cultural allegiance (Widdowson 1990) and linguistic borders. Accordingly, it is anticipated that Arabic and English texts develop some similar tendencies to articulate the general communicative purpose of their academic discourse communities.

Although both the Arab writers and the non-native speakers of English employed similar thanking schematic moves, Arab writers' data exhibit cultural specific differences in the use of generic resources in terms of the type of rhetorical component 
choices, naming practices and organization conventions. With regard to the first point, the Arab writers tend to use certain components such as 'Opening', 'Thanking Allah', 'Invoking and Blessing', 'Closing', and 'Signing off' that do not surface in the English texts analyzed by Hyland (2004). The occurrence of these additional components in the Arabic texts reverberates and reinforces the socio-cultural proclivities of the Jordanian Arab writers explained at the beginning of this section. These culture specific- preferred patterns of discourse also reinforce Hyland's (2005: 197) view that there is 'considerable variation in the role played by metadiscourse in similar genres written in different cultures', as different cultures have different expectations for writing.

As for the second observation, the heading of the Arabic acknowledgements has not achieved the same degree of uniformity in terms of naming conventions as it is the case in English. That is because various nomenclatures are sometimes used as titles for the Arabic acknowledgement section. To illustrate, the title of this section presents writers with several options, the most frequent of which (70\%) is $f u k r$ wa-taqdiir 'Thanks and Appreciation'. Other options are kalimat fukr 'a word of thanks' (12\%), fukr wa-waajib 'thanks and obligation' (5\%), fukr wa-Pihdaa? 'thanks and dedication' (8\%), or simply a one word title $f u k r$ 'Thanks' (5\%). Sometimes, this section is included under the heading of other sections such as the 'Introduction', or mingled with the 'Dedication' section. In other words, the title has not gained a large degree of uniformity in comparison with its English counterpart.

The third point is the observation that the Arabic acknowledgements seem to incorporate a number of epistolary conventions of professional letter genre such as the 'Opening', 'Closing', and Signing off' moves. This was shown in the way twenty-five percent of the Arabic acknowledgements are prefaced with the 'Opening', e.g., 'In the name of Allah'. The 'Closing' move was evident in fifty-two percent of the instances that typically close with ritualistic praises and supplications for Allah. Likewise, the 'Signing off' move which is placed at the end of the text occurred in $20 \%$ of the acknowledgements. These components reflect the epistolary conventions of Arabic professional letters. This tendency suggests that not all of the genre components included in the Arabic acknowledgements are an exclussive property of this particular genre since some ingredient components are likely to be found in other well-established genres (e.g., a typical letter in Arabic). Therefore, one may conclude that these lexical, and generic component options seem to be appropriated (Bhatia 2004: 87-88) to shape a new generic form.

\section{Concluding remarks}

The generic structure which is the overall organization of the acknowledgement text reveals how each component of the text contributes to the overall communicative function of conveying gratitude and thankfulness. The analysis of the corpus revealed that acknowledgement texts comprise a common rhetorical schematic structure built around an eight staged meaningful basic component moves: Opening > Praising and Thanking Allah $>$ Thanking Supervisors and other Academics $>$ Acknowledging Access to Resources > Thanking for Moral Support > Invoking and Blessing > Closing > Signing off (the deictic '>' is used as a 'followed by' sign). However, no single corpus sample contained all of these components and presented in this order. 
The data also exhibits cultural specific differences in the use of generic and lexical resources. It was observed that the Arab writers tend to use certain components such as 'Opening', 'Thanking Allah', 'Invoking and Blessing', 'Closing', and 'Signing off' that do not surface in the English texts. In addition, the grammatical encodings of relative, social and academic status are not only restricted to absolute ritualistic honorifics such as Doctor, Professor, Mr., the Chair, but also include other relational social honorifics, and address forms, borrowed from kinship terms (e.g., Pab 'father', Pax 'brother', Puxt 'sister', and Samm 'uncle') or absolute culture-specific honorifics such as 'sheikh' to express a kind of endearment and solidarity.

Another remark is that conventionally accepted generic forms seem to have given way to accommodate newly accepted practices. This is evenced in the tendency that the Jordanian Arab writers exploit some generic conventions of another wellestablished genre (i.e. letter writing) to communicate socially and academically accepted communicative purposes. Berkenkotter and Huckin (1995: 6) have described genres as inherently dynamic structures that can be manipulated according to the conditions of use. This study of genre acknowledgements in this part of the Arab World is an indication of how genre can be appropriated for the construction of another (Bhatia 2004). This study also has shown that the type of components included in most of the acknowledgements analyzed shows a predispostion to resort to the socio-cultural values which can be attributed to the ideology that characterizes most of the Arab society. At the same time, as already mentioned, some generic practices or writing habits have been borrowed from the West. Sell (1991) believes that 'it is not true to say that people in one culture can never have the faintest idea of what people in other cultures feel' [and that] 'people in different cultures can never feel the same things exactly' (p.14).

So far I have examined how the Arab L1 writers express their thanks and the influence of situational and socio-cultural factors as well as the lexico-grammatical options available to them. However much work remains to be done to find out the boundaries between personal rhetorical choices available to the writers, the options related to the socio-cultural constraints, the ideas borrowed from other dissertations, and those due to the general academic conventions that transcend socio-cultural allegiance. We need qualitative research based on personal interviews with the writers of the acknowledgement genre to tease out their consciousness of their rhetorical choices in the process of production of these texts. The research needs also to be extended to other disciplines, such as hard sciences in Arabic, and to other languages to compare and contrast how gratitude is expressed.

\section{References}

Al-Ali, M. (2004) How to get yourself on the door of a Job: A cross-cultural contrastive study of Arabic and English job application letters. Journal of Multilingual and Multicultural development 25: 1-23.

Al-Ali, M. (2006) Religious affiliations and masculine power in Jordanian wedding invitation genre. Discourse and Society 17.6: 691-714.

Al-Jawziyya, Ibn Qayyim (2000) Suddat Pal- saabiriin wa- ðaxiirat Pal- Saakiriin. Beirut: Pal-maktabah Pal- ؟a sriyyah 
Ali, A. (1989) The Holy Qur'an: Text, Translation and Commentory. Brentwood. MD: Amana.

Bazerman, C. (1984) Modern evolution of the experimental report in physics: Spectroscopic articles in Physical Review, 1893-1980. Social Studies of Science 14: 163-196.

Bazerman, C. (1994) Systems of genres and the enactment of social intentions. In A. Freedman and P. Medway (eds.), Genre and New Rhetoric. London: Taylor \& Francis, pp. 79-101.

Ben-Ari, E. (1987) On acknowledgements in ethnographies. Journal of Anthropological Research 43.1: 63-84.

Berkenkotter, C., and T. Huckin (1995) Genre Knowledge in Disciplinary Communication: Cognition/Culture/Power. Hillsdale, NJ: Lawrence Erlbaum Associates.

Bhatia, V. (1993) Analyzing Genre: Language Use in Professional Settings. London: Longman.

Bhatia, V. (2004) Worlds of Written Discourse. London: Continuum.

Boxer, D. (2002) Applying Sociolinguistics. Amsterdam: John Benjamins Publishing Company.

Brodkey, L. (1987) Academic Writing as Social Practice. Philadelphia: Temple University Press.

Brown, P., and S. Levinson (1987) Politeness: Some Universals in Language Use. Cambridge: Cambridge University Press.

Castleton, B. (2006) Frequency and function of religiously-based expressions. In J.A. Morrow (ed.), Arabic, Islam, and the Allah Lexicon. Lewiston, New York: Edwin Mellen Press, pp. 71-111.

Cronin, B. (1991) Let the credits roll: A preliminary examination of the role played by mentors and trusted assessors in disciplinary formation. Journal of Documentation 47.3: 227-39.

Cronin, B. (1995) The Scholar's Courtesy: The Role of Acknowledgement in the Primary Communication Process. London: Taylor Graham.

Farghal, M. (2002) Situational and discoursal social honorifics in Jordan: An empirical study. International Journal of the Sociology of Language 158: 163-181.

Farghal, M., and A. Shaker (1994) Kin terms and titles of address as relational social honorifics in Jordanian Arabic. Anthropological Linguistics 36.2: 240-53.

Fairclough, N. (1995) Critical Discourse Analysis. London: Longman.

Faruqi, M. (2005) Umma: The orientalists and the Qur'anic concept of identity. Journal of Islamic Studies 16.1: 1-34.

Ferguson, C. (1986) The study of religious discourse. In J. Alatis and D. Tannen (eds.), Language and Linguistics: The Interdependence of Theory, Data and Application. Georgetown Round Table on Languages and Linguistics, 1985, Washington, D.C.: Georgetown Press.

Foley, W. (1997) Anthropological Linguistics. Oxford: Blackwell Publishers.

Genette, G. (1997) Palimpsests. Literature in the Second Degree. Lincoln: University of Nebraska Press.

Giannoni, D. (2002) Worlds of gratitude: A contrastive study of acknowledgement texts in English and Italian research articles. Applied Linguistics 23.1: 1-31. 
Gu, Y. (1990) Politeness phenomenon in modern Chinese. Journal of Pragmatics 14: 237-257.

Halliday, M.K., and R. Hasan (1989) Language, Context, and Text: Aspects of Language in a Socialsemiotic Perspective. Oxford: Oxford University Press.

Harries. L. (1958) Jordan, its People, its Society, its culture. New York: Grove Press.

Holemes, J. (1995) Women, Men and Politeness. London: Longman.

Hyland, K. (2000) Disciplinary Discourses: Social Interactions in Academic Writing. Harlow, England: Pearson Education Limited.

Hyland, K. (2003) Dissertation acknowledgements. Written Communication 20.3: 242-268.

Hyland, K. (2004) Graduates’ gratitude: The generic structure of dissertation acknowledgements. English for Specific Purposes 23: 303-324.

Hyland, K. (2005) Metadiscourse: Exploring Interaction in Writing. London: Continuum.

Hyland, K., and P. Tse (2004) 'I would like to thank my supervisor': Acknowledgements in graduate dissertations. International Journal of Applied Linguistics 14.2: 259-275.

Ide, S. (2005) How and why honorifics can signify dignity and elegance: The indexicality of reflexivity of linguistic rituals. In R. Lakoff and S. Ide (eds.), Broadening the Horizon of Linguistic Politeness. Amsterdam: John Benjamin Publishing Company, pp. 45-64.

Kress, G. (1989) Linguistic Processes in Sociocultural Practice. Oxford: Oxford University Press.

Lee, S. (2002) Politeness and E-mail discourse: A study on the use of linguistic forms of politeness by Chinese learners of English. "Knowledge and discourse: Speculating on disciplinary features", $2^{\text {nd }}$ International Conference, Hong Kong, June, 2002.

Levinson, S. (1983) Pragmatics. Cambridge: Cambridge University Press.

Lu, Y. (2009) Cultural difference of politeness in English and Chinese. Asian Social science 5.6: 154-56.

MacKintosh, K. (1972) Acknowledgement Patterns in Sociology. Oregon: University of Oregon. Unpublished Ph.D. dissertation.

MacCain, K. (1991) Communication, competition, and secrecy: The production and dissemination of research-related information in genetics. Science, Technology and Human Values 16.4: 491-516.

Manno, G. (2005) Politeness in Switzerland: Between respect and acceptance. In L. Hickey and M. Stewart (eds.), Politeness in Europe. Clevedon, UK: Multilingual Matters Ltd., pp. 100-115.

Martin, J. (1992) English Text: System and Structure. Philadelphia/Amsterdam: John Benjamins Publishing Company.

McAuliffe, J. (ed.) (2003) The Encyclopedia of the Qur'an. Leiden, the Netherlands: Brill Academic Publishers.

Miller, C. (1984) Genre as social action. Quarterly Journal of Speech 70: 151-167.

Morrow, J. (2006) The origin of the Allah lexicon. In J.A. Morrow (ed.), Arabic, Islam, and the Allah Lexicon. Lewiston, New York: Edwin Mellen Press, pp. 115-187.

Mursy, A., and J. Wilson (2001) Towards a definition of Egyptian complimenting. Multilingua 20.2: 133154. 
Nelson, G., M. al-Batal, and E. Echols (1996) Arabic and English compliment responses: Potential for pragmatic failure. Applied Linguistics 17.4: 411-32.

Rugh, A. (1985) Family in Contemporary Egypt. Syracuse, New York: Syracuse University Press.

Said, A. (1979) Precept and practice of human rights in Islam. Universal Human Rights 1.1: 64-79.

Samovar, L., and R. Porter (1994) Intercultural Communication: A Reader. California: Wadsworth Publishing Company.

Sell, R. (1991) Literary genre and history: Questions from a literary pragmaticist for socio-semioticians. In E. Ventola (ed.), Approaches to the Analysis of Literary Discourse. Abo: Abo Academy Press, pp. 135.

Swales, J. (1990) Genre Analysis: English in Academic and Research Setting. Cambridge: Cambridge University Press.

Swales, J. (2004) Research Genres: Exploration and Applications. Cambridge: Cambridge University Press.

Swales, J., and C. Feak (1994) Academic Writing for Graduate Students: Essential Tasks and Skills. An Arbor: University of Michigan Press.

Swangboonsatic, C. (2006) Different requestive styles on E-mail between Australians and Thais. NIDA Language and Communication Journal 11.11: 62-84.

Watt, W. (1987) Islamic Political Thought. Edinbugh: Edinburgh University Press.

Widdowson, H. (1990) Aspects of Language Teaching. Oxford: Oxford University Press.

Wierzbicka, A. (1997) Understanding Cultures through Their Key Words. Oxford: Oxford University Press.

Wolfson, N. (1989) Perspectives: Sociolinguistics and TESOL. Cambridge, MA: Newbury House.

Wong, Song Mei-Lee (2000) Cross Cultural Communication: Politeness and Face in Chinese Culture. Frankfurt am Main: Peter Lang.

MOHAMMED NAHAR AL-ALI is an Associate Professor of Applied Linguistics in the Department of English for Applied Studies at Jordan University of Science and Technology/Jordan. He teaches discourse analysis, functional grammar, ESP and linguistics and their applications to language teaching. His articles on genre analysis, register analysis, cross-cultural rhetoric, and pragmatics have appeared in several international journals, such as Discourse and Society. Address: Department of Applied Linguistics, Jordan University of Science and Technology, P.O.B. 3030, Irbid, Jordan. E-mail: alali@just.edu.jo 